\title{
Get Involved: Joy Hines Forsmark
}

\author{
Maria Guzzo
}

"Get Involved" is a recurring End Notes feature that spotlights the work of TMS volunteers and shows the wide range of activities available through TMS. This month, Joy Hines Forsmark, Technical Expert at Ford Motor Company's Research and Advanced Engineering Laboratory, discusses participation with TMS over the past decade - including recognition as a 2013 Brimacombe Medalist - and how it is impacting her career.

Q. It has been 10 years since you received the TMS Young Leader Award. What stands out as your most memorable learning experience during that time?

\begin{abstract}
A. I had the chance to attend the Structural Materials Division council meeting. That really helped me understand the structure of TMS and how we are a member-driven organization. In addition, it was wonderful interacting with members of my Young Leader class, many of whom were in different areas. The annual meeting is a big event, so the Young Leader program is a great way to get to know fellow TMS members. It is one of many things that keep me coming back.
\end{abstract}

Q. How did that experience contribute to further TMS involvement and leadership opportunities?

A. TMS is different from many other organizations in its "bottom-up," "member-driven" approach. I saw that at the council meetings when people were discussing the symposia proposals from their committees. Anyone can submit an idea for a symposium and there are a lot of opportunities for working with the committees.

Q. You also received the TMS Materials Processing \& Manufacturing Division Distinguished Service Award in 2012, chaired the Materials Processing \& Manufacturing Division (MPMD) 2007-2010, organized symposia, sat on the Board and participated in various com- mittees. What role has TMS played in your professional development?

A. TMS has given me tremendous opportunities to take on some highlevel leadership positions at an earlier stage in my career. Serving on the TMS board and chairing the MPMD Council were important growth opportunities that provided me with additional skills to organize and lead projects in my own career. Being in a position to help make decisions at an organizational level gave me insights into the decision-making process at my own company. In addition, organizing symposia has allowed me to interact with some high level people in the materials science field. So that has been fun as well as inspirational.

Q. What has influenced you to remain active in TMS throughout your career?

A. I find tremendous value in the technical content of the TMS annual meeting and the other meetings that TMS produces. I have been able to interact with people who have helped me in my research by giving me insights into problems or new ideas to try. I have learned a lot over the years from folks I first met at a TMS meeting. I feel energized about the field of materials science every time I attend one. Being active in TMS at a leadership level has been rewarding, too. TMS plays a big role in advancing the field of materials science and I like being part of that.

Q. How did you become interested

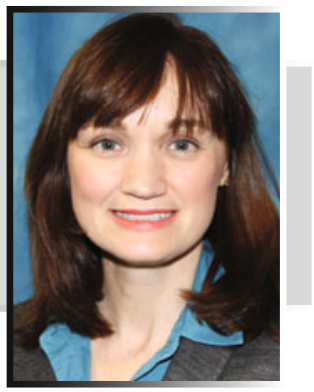

in materials science and engineering specifically?

A. I actually started out as a mechanical engineer at Rice University. However, I took an introduction to materials science course and I was hooked. I thought dislocations, crystal structures and phase diagrams were really cool. I earned my B.S. in the field at Rice then went on to the University of California, San Diego for my master's and Ph.D. in materials science.

Q. What triggered your particular research interests and what else do you hope to achieve in your research area?

A. I am currently working on light cast metals (primarily magnesium and aluminum alloys) for automotive applications and the enablers for those technologies. Lightweighting is an extremely important piece of the puzzle for improving energy efficiency and fuel economy in transportation, so I hope my research can help further those goals.

Q. What would you recommend to organizations such as TMS in growing participation of women in science and engineering, particularly in leadership roles?

A. I think TMS is trying to get more women involved and I encourage women to get involved at the technical committee level, especially.

Maria Guzzo is a contributing writer for JOM. 